NASA Technical Memorandum 105402

$1 N \cdot 176$

.958

$1-9$

\title{
An Overview of Silicon Carbide Device Technology
}

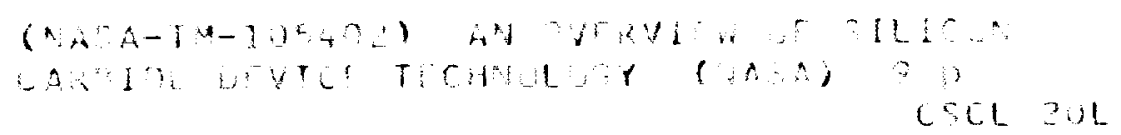

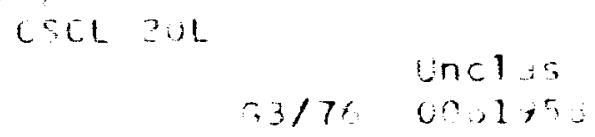

Philip G. Neudeck

Ohio Aerospace Institute

Brook Park, Ohio

and

Lawrence G. Matus

Lewis Research Center

Cleveland, Ohio

Prepared for the

Ninth Symposium on Space Nuclear Power Systems

sponsored by the University of New Mexico

Albuquerque, New Mexico, January 12-16, 1992 
AN OVERVIEW OF SILICON CARBIDE DEVICE TECHNOLOGY

\author{
Philip G. Neudeck \\ Ohio Rerospace Institute \\ 2001 Aerospace Parkway \\ Brook Park, OH $\mathbf{4 4 1 4 2}$
}

\author{
Lawrence G. Matus \\ NASA Lewis Research Center \\ 21000 Brookpark Road \\ Cleveland, OH 44135
}

\section{Abstract}

Recent progreas in the development of silicon carbide (sic) as a semiconductor is briefly reviewed. This material shows great promise towards providing electronic devices that can operate under the high-temperature, high-radiation, and/or high-power conditions where current semiconductor technologies fail. High quality single crystal wafers have become available, and techniques for growing high quality epilayers have been refined to the point where experimental Sic devices and circuits can be developed. The prototype diodes and transistors that have been produced to date show encouraging characteristicg, but by the same token they also exhibit some device-related problems that are not unlike those faced in the early days of silicon technology development. Although these problems will not prevent the implementation of some useful circuits, the performance and operating regime of Sic electronics will be limited until these device-related issues are solved.

\section{INTRODUCTION}

During the past decade, significant progress has been made by a small community of researchers from around the world who are pursuing the development of silicon carbide (SiC) as a semiconducting material. Progress has been made in the important areas of sic crystal growth, crystal characterization, and device fabrication. The interest in $\mathrm{sic}$ is the result of its unique properties which make it attractive for applications requiring electronic devices operating at high temperature, high power, and/or high frequency. Although more work clearly needs to be done, Babcock (1965) suggested that SiC will be tolerant of ionizing radiation environments. Applications for these types of devices are numerous and are found in many industries.

In recent years, the aerospace propulsion and space power communities have expressed a growing need for electronic devices that are capable of sustained high temperature operation. Applications for high temperature electronic devices include development instrumentation within engines such as multiplexers, analog-to-digital converters, and telemetry systems capable of withstanding hot section engine temperatures in excess of $850 \mathrm{~K}$. Similarly, engine mounted integrated sensors and electronics could reach temperatures which exceed $750 \mathrm{~K}$ while uncooled operation of control and condition monitoring equipment in advanced sustained supersonic aircraft is expected to subject electronic devices to temperatures in excess of $573 \mathrm{~K}$ (Nieberding and Powell 1982). Hypersonic vehicles will ultimately pose even more severe temperature demands on electronic devices and integrated sensors.

space-baged systems would also benefit from the existence of high temperature electronic devices. Space applications include power electronic 
devices for space station Freedom, space platforms, and satellites. Since power electronics require radiators to dissipate waste energy (heat), electronic devices that are capable of operating at higher temperatures would allow a reduction in radiator size. This results in a weight savings and thereby reduces the cost of placing the hardware into orbit. Future space nuclear power systems will also require control and condition monitoring circuits for safe and optimum performance. Use of radiation hardened electronic devices would reduce the size of the shield normally used to protect electronic components. If sic devices also prove to be radiation resistant, significant weight savings could be realized.

The need for electronic devices capable of sustained operation at high temperature is not restricted to the aerospace community. Earth-based applications include deep-well drilling instrumentation, power electronics for motor control, nuclear reactor instrumentation and control, and automotive electronics and integrated sensors.

To meet the needs of the applications mentioned above, the High Temperature Electronics Program at the Lewis Research Center is developing SiC as a high temperature semiconductor material. Research is focused on developing the crystal growth, crystal characterization, and device fabrication technologies necessary to produce a family of SiC devices. This paper will first present an overview of the properties of $\mathrm{SiC}$ and then present an overview of the SiC device technology.

\section{SILICON CARBIDE: THE SEMICONDUCTOR}

Silicon carbide (SiC) is familiar to most as the abrasive grit material on sandpaper. It is however, a material that possesses many other unique and useful properties. Sic can also be found in refractory, structural, and electrical applications. An unusual aspect of sic is that its cryatal structure exhibits a form of one-dimensional polytypism. That is, the crystal structures of the many possible polytypes of sic differ from one another only in the stacking sequence of double layers of gilicon and carbon atoms. The Sic polytypes do, however, display differences in electronic and optical properties.

The electronic properties of single-crystal sic, such as its wide energy bandgap, make it particularly attractive for high temperature applications. The bandgap energy of the various polytypes ranges from $2.2 \mathrm{ev}$ to $3.3 \mathrm{eV}$. Presently, the two most commonly studied polytypes of SiC are 3C-SiC, a cubic structure with a $2.2 \mathrm{eV}$ bandgap energy, and $6 \mathrm{H}-\mathrm{sic}$, one of the many possible hexagonal structures. The bandgap energy of $6 \mathrm{H}-\mathrm{SiC}$ is $2.9 \mathrm{ev}$. The maximum operating temperature for a semiconductor material is determined by the bandgap energy, provided of course, that the semiconductor material does not become chemically unstable at lower temperatures. The useful operating temperature limit is reached when the number of intrinsic carriers, thermally excited across the energy bandgap, approaches the number of purposely added (extringic) carriers. For sic with impurity doping levels typical of semiconducting devices, this temperature is well above $1000 \mathrm{~K}$.

A more complete appreciation of the potential of Sic for electronic applications can be gained by examining Table 1, which is a comparison of its properties with the two most common commercially available semiconductors, gilicon (Si) and gallium arsenide (GaAs) and two other contenders for high 
temperature applications, gallium phosphide (GaP) and diamond. In the sic column of the table, the quantities in parenthesises pertain to $6 \mathrm{H}-\mathrm{Sic}$. The maximum operating temperature for these semiconductors was calculated relative to that of $\mathrm{Si}$ by assuming a maximum for $\mathrm{Si}$ of $600 \mathrm{~K}$ and multiplying this temperature by the ratio of the bandgap energies. In comparing the potential candidate materials for high temperature semiconductor devices, SiC also stands out because it is a very stable ceramic material up to temperatures of $2100 \mathrm{~K}$. The combination of high breakdown field (tolerant of high electric fields) and high thermal conductivity (heat transfer) provides the potential for improved power electronic systems and for an increased number of devices per unit area. Those properties which determine the high frequency characteristics of semiconductor devices are also excellent for sic. From a theoretical point of view, the properties of sic result in a higher figure-ofmerit for it than for other available semiconductor materials which are candidates for high-power or high-frequency electronic devices capable of high temperature operation (Shenai et al. 1989 and Baliga 1989).

Component reliability is a key issue in all aerospace applications because failure can lead to expensive or tragic consequences. Electronic devices or sensors that are capable of operating at high temperatures have the immediate payoff of improved reliability when operated at lower temperatures. For example, if electronic devices capable of $573 \mathrm{~K}$ operation possess the same failure rate at $573 \mathrm{~K}$ as devices specified for $400 \mathrm{~K}$ operation, the failure rate will be reduced by 1000 when the " $573 \mathrm{kn}$ electronic devices are operated in a $400 \mathrm{~K}$ environment. This three orders of magnitude improvement in reliability is due to the exponential dependence of failure rates on temperature. Based on its properties, the reliability of electronic devices and sensors fabricated from SiC should be much higher than that obtained from any current semiconductor material operated under the same conditions.

\section{SIC DEVICE TECHNOLOGY}

Sic device technology has been developing for more than thirty years. The major impediment to this development had been the lack of single-polytype sic substrates of sufficient quality and size. A significant breakthrough in SiC growth was made by Tairov and Tsvetkov (1978), who pioneered the modified sublimation process for growing SiC boules. More recently, a SiC research team (Carter et al. 1987) at North Carolina State University announced the successful implementation of a seeded-growth sublimation method to produce the $6 \mathrm{H}-\mathrm{SiC}$ polytype in boule form. A private company, Cree Research Inc., has developed this process to the point where one inch diameter wafers of $6 \mathrm{H}-\mathrm{SiC}$ are now commercially available. The significance of this accomplishment is that these $6 \mathrm{H}-\mathrm{SiC}$ crystals can now be used as substrates for sic epitaxial growth via the chemical vapor deposition (CVD) processes already developed at the Lewis Research Center (Powell et al. 1990).

$6 \mathrm{H}-\mathrm{SiC}$ appears to be the most attractive polytype for developing useful electronic circuits at this time, but this is simply because current crystal growth techniques produce substantially higher quality $6 \mathrm{H}$ material than other Sic polytypes. With unintentional background carrier concentrations in the mid-10 $\mathrm{cm}^{-3}$ range being grown (Palmour et al. 1991), the quality of epitaxial $6 \mathrm{H}-\mathrm{SiC}$ is clearly sufficient to permit fabrication of discrete devices and small integrated circuits. $n-$ and $p$-type doping of $3 \mathrm{C}$ and $6 \mathrm{H}$ epilayers can be controlled during epitaxial growth, so a variety of device structures can be produced in a relatively straightforward manner. 
Much of the technology required to produce working electronic circuits in Sic is directly importable from well-developed silicon processing technologies, so the jump to higher levels of integration should not be exceedingly difficult after individual sic devices are mastered. Standard techniques for photolithographic pattern definition and material (dielectrics, metals, etc.) deposition are directly applicable to the fabrication of sic device structures. Patterned doping of SiC can be accomplished through ion implantation, but this is usually carried out at elevated substrate temperatures to achieve proper dopant activation (Edmond et. al. 1986). Diffusion of dopants into SiC is not practical as diffusion coefficients are negligible below $2100 \mathrm{~K}$; however, this property is actually an advantage during high-temperature operation as dopants will not redistribute. The inherent mechanical toughness of SiC helps prevent wafer breakage during processing, but its chemical inertness precludes the use of conventional wet etching at room temperature. Satisfactory etching of SiC is accomplished primarily by reactive ion etching (RIE) (Pan and Steckl 1990).

Besides the inherent material properties outlined previously, perhaps one of silicon carbide's biggest assets is its ability to thermally grow a passivating native oxide just like silicon. When SiC is thermally oxidized it produces $\mathrm{SiO}_{2}$, the same insulator that is produced when pure silicon is thermally oxidized. The importance of this Sic property should not be underestimated as the majority of all integrated circuits (IC's) are based on the $\mathrm{Si}^{-\mathrm{SiO}_{2}}$ MOSFET (Metal Oxide Semiconductor Field Effect Transistor) -- a device which relies on thermally grown silicon dioxide!

A fundamental building block of any semiconductor technology is the junction, especially as it pertains to trangistor performance. JFET's (Junction Field Effect Transistors) and BJT's (Bipolar Junction Transistors) rely on p-type to n-type junctions (i.e., pn junctions), MESFET's (Metal semiconductor Field $\mathrm{Effect}$ Transistors) rely on rectifying metal-semiconductor junctions (i.e., schottky junctions), MOSFET's rely on insulator-semiconductor junctions, and all of these devices require ohmic contact junctions. It therefore follows that the ultimate performance capabilitieg of these transistors are largely dependent on one's ability to form junctions with desirable characteristics. Although research into the optimization of Sic junction qualities is far from mature, a variety of early experimental $6 \mathrm{H}-\mathrm{SiC}$ devices have produced some tantalizing results.

In the case of the pn junction, low leakage currents and high reverse breakdown voltages are desireable in most applications. Figure 1 shows the room-temperature current vs. voltage (I-V) characteristic of a pn junction diode fabricated in epitaxially grown $6 \mathrm{H}$ SiC (Matus et al. 1991). The $v_{\text {breakdown }}>1000 \mathrm{~V}$ at the doping level of $2 \times 10^{16} \mathrm{~cm}^{-3}$ for the diode $\mathrm{n}-$ region demonstrates the significantly higher breakdown field enjoyed by $6 \mathrm{H}-\mathrm{SiC}$ over $\mathrm{Si}$ and GaAs (Table 1). This 10-fold increase in field strength for SiC theoretically translates into considerable improvements in the characteristics and operating regime of many power semiconductor devices (Baliga 1991). General semiconductor device physics suggests that the large bandgap (small intrinsic carrier concentration) of SiC should lead to greatly reduced pn junction ieakage currenta. Gardner et al. (1991) have reported 6H-SiC pn junction leakages which are orders of magnitude smaller than leakages reported in similar GaAs structures. 
Early experiments have suggested that sic devices are inherently more radiation tolerant than comparable silicon devices (Yoshikawa et al. 1991), but wider ranging radiation tolerence studies are currently being undertaken.

Experimental JFET's, MOSFET's (Figure 2), MESFET's, and BJT's have been fabricated in single crystal $6 \mathrm{H}-\mathrm{SiC}$, and basic operation of these devices at temperatures as high as $923 \mathrm{~K}$ has been demonstrated (Davis et al. 1991). No other semiconductor material has shown transistor operation at this temperature. However, these devices exhibit several significant shortcomings which point out fundamental challenges that remain to be solved if $\mathrm{SiC}$ is to emerge as a truly advantageous semiconductor for high-temperature, highradiation, and/or high-power applications.

At $923 \mathrm{~K}$ the operational lifetime of these transistors is typically less than $1 / 2$ hour. This limitation is strictly due to failure of non-optimized ohmic contact metallizations, and it is not due to any limitations of the Sic semiconductor itself. Reliable contacts to SiC have been demonstrated for 623 $\mathrm{K}$ operation, but a crucial area of continued research is to develop ohmic contacts that will remain stable at temperatures approaching $900 \mathrm{~K}$ and beyond. The progress that is made in obtaining reliable high-temperature contacts will largely dictate the operational temperature ceiling of Sic electronics.

Besides the ohmic contact, another fundamental sic junction that needs

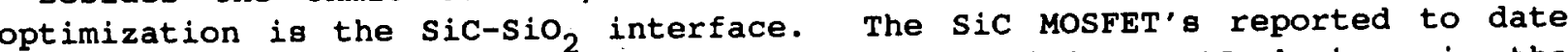
suffer from the same major problem that faced silicon MOS devices in the 1960's; interface states. Dangling bonds and surface disorder at the semiconductor-insulator boundary give rise to electrically active defect states. These defect states hinder the ability of the MOSFET to carry current (because of decreased channel carrier mobilities), and cause charge trapping that results in undesirable threshold voltage instability. If one draws upon the historical parallel with silicon MOS technology, it stands to reason that the performance of SiC MOSFET's should improve substantially when interface state densities are reduced from their current levels of $10^{12-13} \mathrm{~cm}^{-2}$ to the $10^{10} \mathrm{~cm}^{-2}$ densities found in modern silicon MOSFET's. It should be noted that MOSFET's are not the only class of device that stands to gain from improved oxide-sic interface charactersitics. Gardner et al. (1991) have recently shown that passivating oxide quality dramatically affects the leakage characteristics of SiC pn junctions.

\section{CONCLUSION}

With the mastering of $6 \mathrm{H}-\mathrm{SiC}$ crystal growth, tremendous strides have been made in the development of $\mathrm{SiC}$ as a semiconductor for high-temperature, highradiation, and/or high-power electronic applications. However, some crucial device-related issues remain to be solved before the true performance potential of SiC electronic devices can be evaluated. Clearly, improvements need to be made in the areas of contact metallization and the $\mathrm{SiC}^{-\mathrm{SiO}_{2}}$ interface. It is the authors' opinion that the resolution of these key issues and subsequent development of SiC into integrated electronics will be substantially accelerated by the vast knowledge base that has been accumulated in silicon IC technology. It is hoped that this emerging technology will soon be capable of playing a role in the advancement of space power systems. 


\section{Acknowledgments}

The work described herein was performed at the NASA Lewis Research Center under internal funding support.

\section{References}

Babcock, R. (1965) "Radiation Damage in SiC," IEEE Trans. Nucl. Sci. NS-12:4347.

Baliga, B. J. (1989) "Power Semiconductor Device Figure of Merit for HighFrequency Applications," IEEE Electron Device Lett., EDL-10(10): 455-457.

Baliga, B. J. (1991) "Impact of SiC on Power Devices," in 4th International Conference on Amorphous and Crystalline silicon Carbide and other IV-IV Materials, held in Santa Clara, CA, 10-11 October 1991.

Carter, Jr., C. H., L. Tang, and R. F. Davis (1987) "Sublimation Growth of Large 6H-SiC Single Crystals," Presented at the Fourth National Review Meeting on the Growth and Characterization of SiC, Raleigh, NC.

Davis, R. F., G. Kelner, M. Shur, J. W. Palmour, and J. A. Edmond (1991) "Thin Film Deposition and Microelectronic and Optoelectronic Device Fabrication and Characterization in Monocrystalline Alpha and Beta Silicon Carbide," Proc. IEEE, Vol. 79, No. 5, pp. 677-701.

Gardner, C. T., J. A. Cooper, Jr., M. R. Melloch, J. W. Palmour, and C. H. Carter, Jr. (1991) "Electrical Characterization of PiN Diode Structures in 6HSic," in 4th International Conference on Amorphous and Crystalline silicon Carbide and Other IV-IV Materials, held in Santa Clara, CA, 10-11 October 1991.

Matus, L. G., J. A. Powell, and C. S. Salupo (1991) "High-Voltage 6H-SiC p-n Junction Diodes," Appl. Phys. Lett. 59(14): 1770-1772.

Nieberding, W. C., and J. A. Powell (1982) "High-Temperature Electronic Requirements in Aeropropulsion systems," IEEE Trans. on Industrial Electronics, IE-29(2): 103-106.

Palmour, J. W., J. A. Edmond, H. S. Kong, and C. H. Carter, Jr. (1991) "Applications of $6 \mathrm{H}-\mathrm{Silcon}$ Carbide Devices," in $4 \mathrm{th}$ International Conference on Amorphous and Crystalline Silicon Carbide and other IV-IV Materials, held in Santa Clara, CA, 10-11 October 1991.

Pan, W. S., and A. J. Steckl (1990) "Reactive Ion Etching of SiC Thin Films by Mixture of Fluorinated Gases and Oxygen," J. Electrochem. Soc., Vol. 137, pp. 212-220.

Powell, J. A. et al. (1990) "Growth of High Quality 6H-SiC Epitaxial Films on Vicinal (0001) 6H-SiC Wafers," Appl. Phys. Lett., 56(15): 1442-1444.

Shenai, K., R.S. Scott, and B.J. Baliga (1989) "Optimum semiconductors for High-Power Electronics," IEEE Trans. Electron Deviceg, ED-36(9):1811-1823. 
Tairov, Y.M. and V.F. Tsvetkov (1978) "Investigation of Growth Processes of Ingots of Silicon Carbide single Crystals," J. Crystal Growth, 43:209-212.

Yoshikawa, M., H. Itoh, Y. Morita, I. Nashiyama, S. Misawa, H. Okumura, and S. Yoshida, (1991) "Effects of Gamma-Ray Irradiation on Cubic Silicon Carbide Metal-oxide-Semiconductor Structure," J. Appl. Phys. 70(3): 1309-1312.

TABLE 1. Comparison of Semiconductors.

\begin{tabular}{|c|c|c|c|c|c|}
\hline Froperty & $\mathrm{Si}$ & GaAs & GaP & 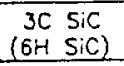 & Dicmond \\
\hline $\begin{array}{l}\text { Bondgcp }(\mathrm{ev}) \\
\text { ot } 3 \mathrm{Cok} \mathrm{K}\end{array}$ & 1.1 & 1.4 & 2.3 & \begin{tabular}{|c|}
2.2 \\
$(2.9)$ \\
\end{tabular} & 5.5 \\
\hline $\begin{array}{l}\text { Hoximum operating } \\
\text { tempercture }(K)\end{array}$ & 600 & 760 & 1250 & $\begin{array}{c}1200 \\
(1580)\end{array}$ & $1400(?)$ \\
\hline Meiting point (K) & 1690 & 1510 & 1740 & $\begin{array}{l}\text { Sublimes } \\
>2100\end{array}$ & $\begin{array}{l}\text { Phase } \\
\text { change }\end{array}$ \\
\hline Physicol stobility & Good & Foir & Foir & Excellen: & Very good \\
\hline $\begin{array}{l}\text { Electron mobility } \\
\text { R.T., } \mathrm{cm}^{2} / \mathrm{V}-\mathrm{s}\end{array}$ & 1400 & 8500 & 350 & $\begin{array}{l}1000 \\
(600) \\
\end{array}$ & 2200 \\
\hline $\begin{array}{l}\text { Hole motility } \\
\text { R.T., } \mathrm{cm}^{2} / \mathrm{v}-\text { s }\end{array}$ & 600 & 400 & 100 & 40 & 1600 \\
\hline $\begin{array}{l}\text { Ereokdown volloge } \\
E_{5} .10^{0} \mathrm{~V} / \mathrm{cm}\end{array}$ & .3 & .4 & - & 4 & 10 \\
\hline $\begin{array}{l}\text { Thermei conductivity } \\
\epsilon_{-}, \mathrm{w} / \mathrm{cm}-\mathrm{C}\end{array}$ & 1.5 & .5 & .8 & 5 & 20 \\
\hline $\begin{array}{l}\text { Sot. elec. drift vel. } \\
\mathrm{x}(\mathrm{sot}), 10^{7} \mathrm{~cm} / \mathrm{s}\end{array}$ & 1 & 2 & - & 2.5 & 2.7 \\
\hline Cie!ectric consi., K & 11.8 & 12.8 & 11.1 & 9.7 & 5.5 \\
\hline
\end{tabular}

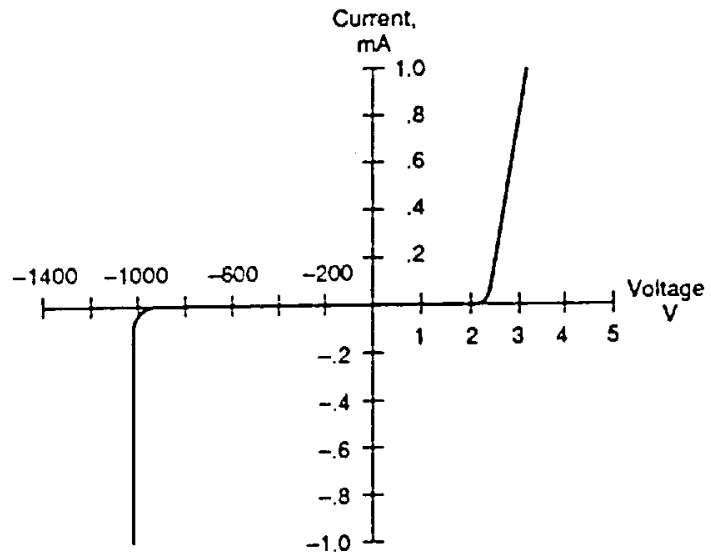

Figure 1. IV characteristics of a $6 \mathrm{H}-\mathrm{SiC}$ pn junction diode tested at room temperature.

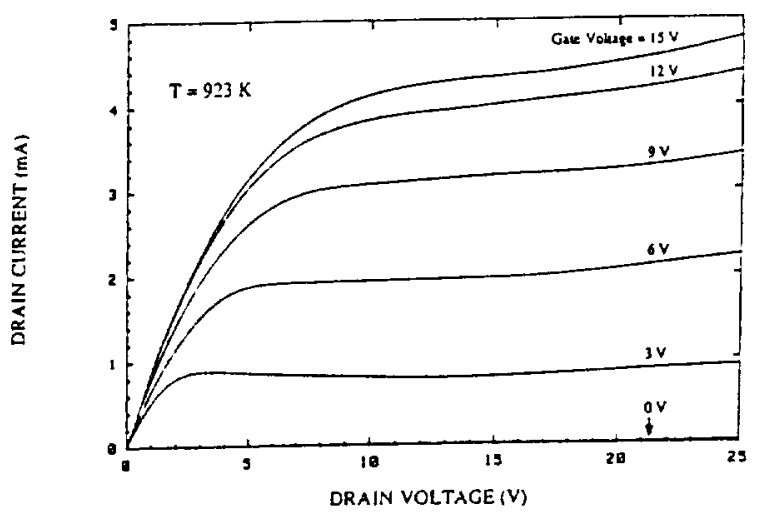

Figure 2. Drain IV characteristics of an inversion-mode $6 \mathrm{H}-\mathrm{SiC}$ MOSFET tested at $923 \mathrm{~K}$. (Courtesy of Cree Research Inc.) 
Public reporting burden for this collection of information is estimated to average 1 hour per response, including the time for reviewing instructions, searching existing data sources, gathering and maintaining the data needed, and completing and reviewing the collection of intormation. Send comrments regarding this burden estimate or any other aspect of this collection of information, including suggestions for reducing this burden, to Washington Headquarters Services, Directorate for information Operations and Reports, 1215 Jefferson Davis Highway, Suire 1204, Arlington, VA 22202-4302, and to the Office of Management and Budget, Paperwork Reduction Project (0704-0188). Washington, DC 20503.

\begin{tabular}{|c|c|c|}
\hline 1. AGENCY USE ONLY (Leave blank) & $\begin{array}{r}\text { 2. REPORT DATE } \\
1992\end{array}$ & $\begin{array}{l}\text { 3. REPORT TYPE AND DATES COVERED } \\
\text { Technical Memorandum }\end{array}$ \\
\hline
\end{tabular}

4. TITLE AND SUBTITLE

5. FUNDING NUMBERS

An Overview of Silicon Carbide Device Technology

Philip G. Neudeck and Lawrence G. Matus

WU $-505-62-50$

6. AUTHOR(S)
Philip G. Neudeck and Lawrence G. Matus

7. PERFORMING ORGANIZATION NAME(S) AND ADDRESS(ES)

National Aeronautics and Space Administration

Lewis Research Center

Cleveland, Ohio $44135-3191$

8. PERforming organization REPORT NUMBER

$E-6803$

9. SPONSORING/MONITORING AGENCY NAMES(S) AND ADDRESS(ES)

10. SPONSORING/MONITORING AGENCY REPORT NUMBER

National Aeronautics and Space Administration

Washington, D.C. 20546-0001

NASA TM - 105402

11. SUPPLEMENTARY NOTES

Prepared for the Ninth Symposium on Space Nuclear Power Systems sponsored by the University of New Mexico, Albuquerque, New Mexico, January 12-16, 1992. Philip G. Neudeck, Ohio Aerospace Institute, 2001 Aerospace Parkway, Brook Park, Ohio 44142. Lawrence G. Matus, NASA Lewis Research Center. Responsible person, Lawrence G. Matus, (216) 433-3650.

12a. DISTRIBUTION/AVAILABILITY STATEMENT

12b. DISTRIBUTION CODE

Unclassified - Unlimited

Subject Category 76

13. ABSTRACT (Maximum 200 words)

Recent progress in the development of silicon carbide ( $\mathrm{SiC}$ ) as a semiconductor is briefly reviewed. This material shows great promise towards providing electronic devices that can operate under the high-temperature, highradiation, and/or high-power conditions where current semiconductor technologies fail. High quality single crystal wafers have become available, and techniques for growing high quality epilayers have been refined to the point where experimental SiC devices and circuits can be developed. The prototype diodes and transistors that have been produced to date show encouraging characteristics, but by the same token they also exhibit some device-related problems that are not unlike those faced in the early days of silicon technology development. Although these problems will not prevent the implementation of some useful circuits, the performance and operating regime of SiC electronics will be limited until these device-related issues are solved.

\begin{tabular}{|c|c|c|c|}
\hline \multicolumn{3}{|c|}{$\begin{array}{l}\text { 14. SUBJECT TERMS } \\
\text { Silicon carbide; Semiconductor; Electronic devices; High temperature }\end{array}$} & \begin{tabular}{|c|} 
15. NUMBER OF PAGES \\
8 \\
16. PRICE CODE \\
A02 \\
20. LIMITATION OF ABSTRACT
\end{tabular} \\
\hline
\end{tabular}


National Aeronautics and Space Administration

Lewis Reseurch Conter Cleveland, Ohio 44135

Omaled Bundnews

Penchy for Private Uee $\$ 900$
FOUFTH CLASS MAIL

\section{ADDRESS CORAECTION REQUESTED}

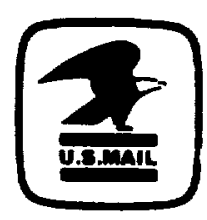

Postage and Fees Paid National Aeronautics and Space Adminisiralion NASA 451 